\title{
Capability Analysis and use of Acceptance and Control Charts in the 6-Sigma in Pharmaceutical Industries Case Study: Behestan Tolid Pharmaceutical Co
}

\author{
Taher Taherian \\ $\mathrm{PhD}$ in Industrial Engineering, \\ Quality Assurance Expert, \\ Behestan Tolid Pharmaceutical Company, \\ Kaveh Industrial Town, Iran
}

\author{
Mehdi Balouchestani Asl \\ Pharm D, Managing Director, \\ Behestan Tolid Pharmaceutical Company, \\ Kaveh Industrial Town, Iran
}

\begin{abstract}
Different Industries use the acceptance charts to assess if the process could meet customer specified requirements because the acceptance charts are competent tool to answer the critical question that's to see if the process average stays between acceptable levels so the final product meets the customer specification levels. Also process capability determines that if the manufacturer could meet customer's requirements or should improve its process by reducing the process variation and fitting it's mean. What is discussed in this paper, is the use of the mentioned charts in 6-Sigma applications and how the capability analysis results help to know the status of production specifications. A case-study as an example is included to clarify the acceptance chart concepts.
\end{abstract}

\section{General Terms}

Behestan Tolid, Pharmaceutical Company, Statistical Process Control. Tablet manufacturing industry, Control Charts, Tablet manufacturing. Process validation

\section{Keywords}

Behestan Tolid Pharma Co, Acceptance charts, Process Capability, Process Performance, Cpk, Ppk . Customer Requirements, ACL, APL. Six- Sigma. Sandoz-Hexal Pharmaceutical Company. Astellas Pharma Inc

\section{INTRODUCTION}

Acceptance control charts combines consideration of control concepts with the important elements of acceptance sampling. It's a suitable tool helps to have a good decision making with respect to the process acceptance. It makes clear that whether or not a selected percentage of units of a product came out from the process will satisfy the customer specified requirements. Acceptance control charts are different from the Shewhart Control Charts, but usually the process doesn't need to be in control about a single standard process level until the within-subgroup variability remains in control and is much smaller than the tolerance distance. It means that the variability of subgroup means may be in control but a remarkable percentage of the process exceeds the tolerance specification limits. Monitoring the variables using Shewhart control charts uses to confirm the steady state of inherent variability of subgroups so a Shewhart control charts are used to verify the validity of using an acceptance control chart; so we use the acceptance control charts when the within subgroup variation is in control and a high level of process capability has been achieved. In other hands, in some processes, there are some natural shifts in the process average but the process still produces the products in the range of customer required specifications. This means that in this state, the standard deviation of the average values of that process is so small relative to the specification width. As mentioned, in shewhart statistical process control charts, it is possible that a process has not considered in-control but it still may be able to produce in acceptable range. So in some situations we don't prefer to answer the question "is the process in control?" because actually it's important to know the answer of "is my process produce defective parts?". Acceptance charts are useful for this situations. The acceptance control chart is based on the shewhart control charts but in acceptance control chart, the process mean can shift outside of upper and lower control limit (UCL \& LCL) if the specifications are so wide. Also if the inherent variability of the process is so large it can be restricted to narrower limits.

Freund (1957) [1] presented this idea for first time which won lots of awards and known as the best contribution of that time. Duncan (1986) [2] and Montgomery (1996) [3] developed more extension for that first idea until Edward (2008) [4] published a book titled "acceptance sampling in quality control" and presented the most widely used techniques for acceptance of the industrial processes as a good source for information on sampling according to the Mil Specifications according to ISO 7870-3.

6-Sigma, is a data driven method for eliminating the defect which are within Six standard deviation between the mean and both upper and lower specification limits. 6-sigma as a tool for process improvement was introduced by an engineer working in Motorola, Bill Smith (1986) [5]. Nowadays, Popularity of Six-Sigma is not limited just to manufacturing organizations and the service organizations uses its concepts to improve their processes. 6-sigma means statistically, no more than 3.4 PPM as defects in any process, product or service, Hary (2009) [6]. This quality level, assume that the process mean may shift as much as $\pm 1.5 \sigma$. this fluctuation in mean translates in to a $4.5 \sigma$ quality level which reflects about 3.4 Parts per million opportunities as defects. An acceptance chart, can be designed to determine if the process mean has shifted more than the allowance interval, i.e., $\pm 1.5 \sigma$. Chiarini (2011) [7] introduced the Japanese total quality control and lean six sigma concepts.

Pharmaceutical industries produce their products in a multistep processes. Each step named "unit operation" produce an intermediate product with a specified quality that ensure the acceptable final product qualities. One of the widely used 
dosage forms in drug product manufacturing is Tablet which usually, weighing, blending, granulating, compression, coating and packaging (primary and secondary) are different unit operations. There are some variabilities available in each powder "lot" which is processed in each unit of operation, Between lot variability and the within lot variability. also there are some critical quality attributes in each produced tablet such as, tablet Hardness (tensile strength), friability, disintegration, dissolution and thickness (dimension), content uniformity, tap density and etc.

Actually these critical quality attributes must be controlled in tablet production processes to satisfy the customer requirements. this paper tries to show the implementation of some statistical process control like shewhart control charts, acceptance control charts during 6-sigma concepts. Patel (2015) [8] showed how statistical process control could be used to control weight uniformity of tablets. Hashmat et al. (2008) [9], used shewhart quality control plots for tablet hardness, tablet thickness and weight variation of tablets. Brochmann and medin (2006) [10] considered the variation in weight and variation in percent composition as two sources of variability affecting the drug dosage in tablet.

This paper tries to present the implementation of SPC during Process validation of tablet manufacturing because it's a fundamental component in pharmaceutical industry that supports a company commitment to QA. Surbhi et al. (2012) [11] presented an overview from the industrial process validation of tablet dosage form in pharmaceutical industries.

\section{METHODOLOGY}

This paper describes how an acceptance chart based on AQL, RQL is created.

Four elements required to create an acceptance control chart are as follows:

a. an acceptable process level (APL) associated with $\alpha$ risk.

b. a rejectable process level (RPL) associated with the $\beta$ risk.

c. an action criterion or acceptance control limit (ACL).

The sample size

Figure 1 shows the acceptable, rejectable area and indifference zone:

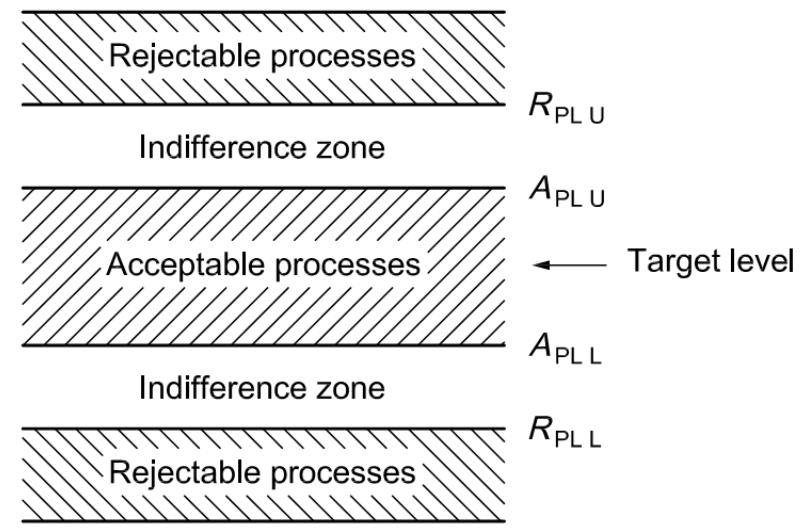

Fig 1: Two-sided specification limits in relation to processes of acceptable, rejectable $\&$ indifference quality
APL is called acceptable process level which is as a line that distinguishes a good from an unsatisfactory quality level and represents a process that should be accepted almost $(1-\alpha)$. It marks the outer boundary of the central zone (acceptable process zone about the target value).

RPL is a process level that demonstrate processes that should almost never be accepted (1- $\beta)$.

Any process centered far from the APL and so closer to the target is equal to have a risk smaller than $\alpha$ of not being accepted.

\section{Symbols:}

$A C L \quad$ acceptance control limits

$A P L \quad$ acceptance process limit

$R P L \quad$ rejectable process level

USL upper specification limit

LSL lower specification limit

P0 acceptable proportion nonconforming items (AQL)

P1 rejectable proportion nonconforming items (RQL)

$\alpha \quad$ risk of not accepting a process centered ant the APL

$\beta \quad$ risk of not rejecting a process centered at the RPL

$\mu \quad$ process mean

z variable that has Standard Normal distribution

$\sigma_{\mathrm{x}} \quad$ within subgroup ST deviation corresponding to the inherent process variability

It's estimated by shewhart control chart techniques

$\sigma_{\mathrm{x}}=\frac{\overline{\mathrm{R}}}{\mathrm{d}_{2}}$ or $\frac{\overline{\mathrm{S}}}{\mathrm{c}_{4}}$

$\sigma_{\overline{\mathrm{x}}}$ standard deviation of subgroup average corresponding to the inherent process variability

$\sigma_{\overline{\mathrm{x}}}=\sigma_{\mathrm{x}} / \sqrt{\mathrm{n}}$

The steps of creating an acceptance control chart:

St 1. Choose both of AQL an RQL suitable for process.

St 2. Make acceptance process limit (APL) with making distance downwards from the USL with the amount of $\mathrm{k}_{1} \sigma_{\mathrm{x}}$.

$$
\begin{array}{lcr}
\mathrm{APL}_{\mathrm{u}}=\mathrm{USL}-\mathrm{k}_{1} \sigma_{\mathrm{x}} & \text { Which } & \mathrm{k}_{1}=\mathrm{Z}_{\mathrm{p} 0} \\
\mathrm{APL}_{\mathrm{l}}=\mathrm{LSL}+\mathrm{k}_{1} \sigma_{\mathrm{x}} & \text { Which } & \mathrm{k}_{1}=\mathrm{Z}_{\mathrm{p} 0}
\end{array}
$$




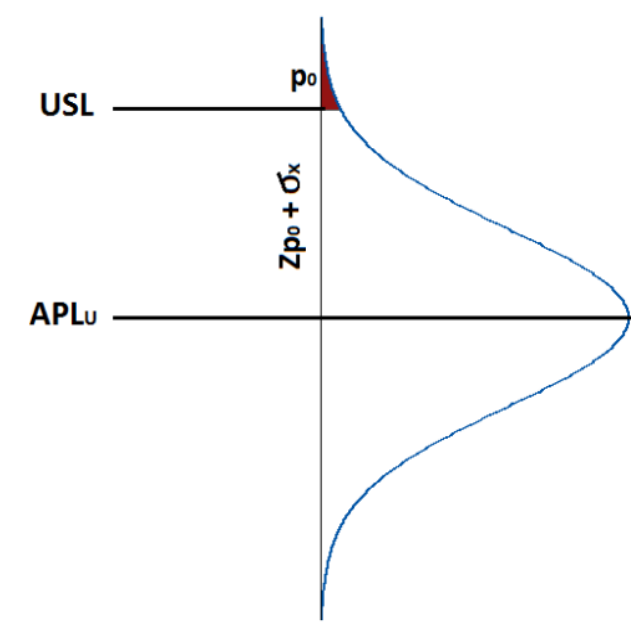

Fig 2: Determination of APL from distribution of individuals

St 3. Make rejectable process level (RPL) with making distance downwards from the USL with the amount of $k_{2} \sigma_{x}$.

$R P L_{u}=U S L-k_{2} \sigma_{x} \quad$ Which $\quad k_{2}=Z_{p 1}$

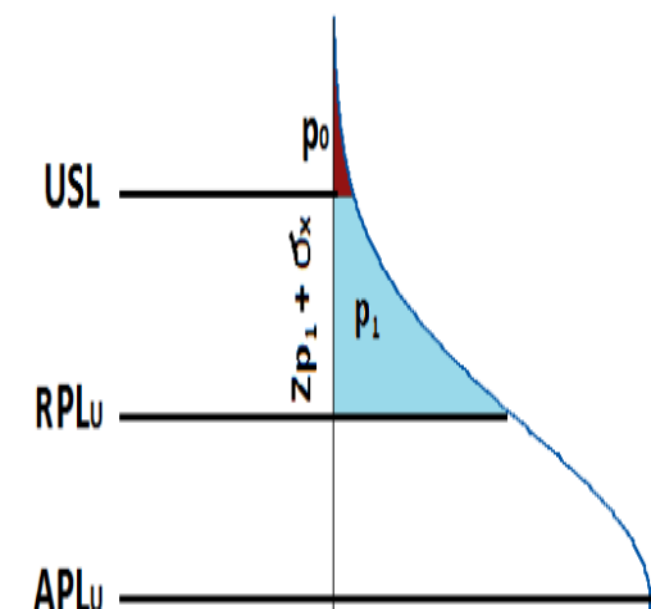

Fig 3: Determination of RPL from distribution of individuals

St 4. Add $k_{2} \sigma_{\bar{x}}$ to APLu to make upper acceptance control limit (ACLu)

$A C L_{u}=A P L_{u}+Z_{\alpha} \sigma_{\bar{x}}=A P L_{u}+\sigma_{x} Z_{\alpha} / \sqrt{n}$

$A C L_{l}=A P L_{l}-Z_{\alpha} \sigma_{\bar{x}}=A P L_{l}-\sigma_{x} Z_{\alpha} / \sqrt{n}$

Also we will have another equation for RPL:

$R P L_{u}=A C L_{u}+Z_{\beta} \sigma_{\bar{x}}$

$R P L_{l}=A C L_{l}-Z_{\beta} \sigma_{\bar{x}}$

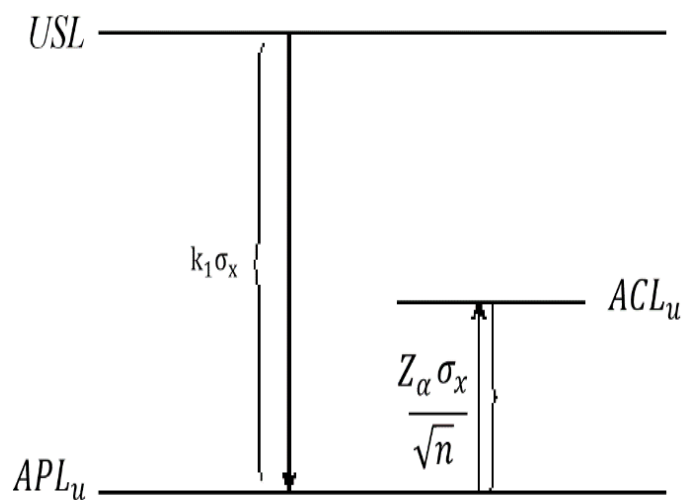

Fig 4: Determination of ACL from distribution of averages

the sample averages values between $A C L_{l}$ and $A C L_{u}$ lead to acceptance the process, it means that it produces items meeting both specification limits of USL and LSL, respectively.

The sample size could be calculated as

$$
n=\max \left\{\left[\frac{\left(Z_{\alpha, u}+Z_{\beta, u}\right) \cdot \sigma_{x}}{R P L_{u}-A P L_{u}}\right]^{2} \text { or }\left[\frac{\left(Z_{\alpha, l}+Z_{\beta, l}\right) \cdot \sigma_{x}}{R P L_{l}-A P L_{l}}\right]^{2}\right\}
$$

If we assume $Z_{\alpha}=3$ and $Z_{p_{0}}=3$, it's corresponding to the 0.9974 probability of accepting the 0.0026 defective process which means $\mathrm{AQL}=0.0026$.

\section{Tablet manufacturing quality attributes}

This paper tries to implement statistical process control in Process Validation phase of tablet manufacturing. The main goal of process validation in pharmaceutical industries is to confirm that the process can reliably produce in determined standard. This analysis uses gathered data throughout the design and manufacturing of the product with the purpose of ensuring varied inputs lead to consistent and high quality outputs. In process validation, the company makes a batch of product (ex. Tablet) from the beginning process to the end and takes some in-process tests and finished product test to ensure the product standard qualifications.

According to the tablet type, Process validation can be run in all tablet manufacturing processes includes weighing, binder solution (solution preparation vessel), Sifting, dry and wet granulating (high shear mixer), drying (Fluid bed dryer (FBD)), milling (Conical mill), blending (lubrication), compression, coating, and packaging (blistering and secondary packaging).

In process validation, tablets are produced without any drug substance, called Placebo; other than the Assay Test and content uniformity, about all physical and chemical in-process and final tests would be done.

Some of critical attributes in tablet production are, tablet hardness (tensile strength), friability, disintegration, dissolution, and tablet thickness (dimensions), average weight.

Granules are tested for content uniformity (not for process validation), flow rate, tap density, moisture content (LOD).

During compression process, tablets are tested for weight, thickness, friability and disintegration. Finished-product tests are about appearance, weight, friability, assay, content 
uniformity (not for process validation), disintegration dissolution and impurity profile.

Figure 5, shows the pharmaceutical in-process control flow chart.

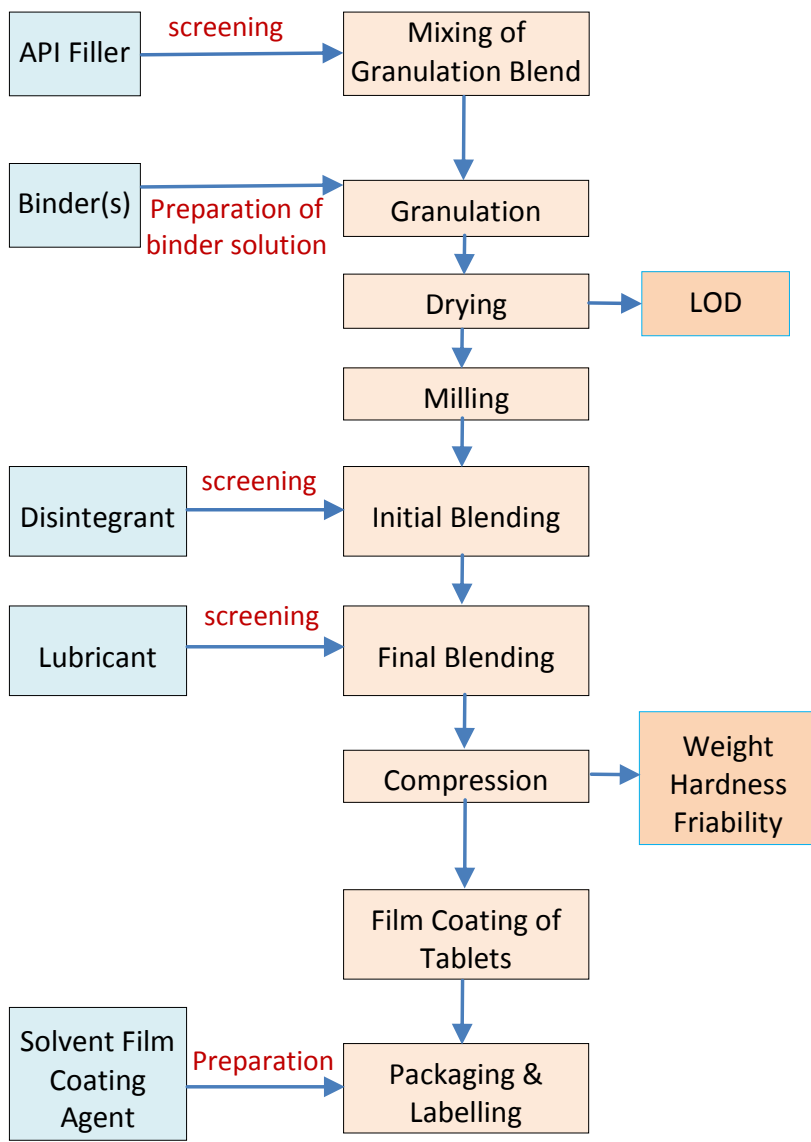

Fig 5: Tablet production in-process flowchart

Table 1. Tablet Manufacturing Process Critical Parameters

\begin{tabular}{|c|c|c|}
\hline $\begin{array}{l}\text { Control } \\
\text { variable }\end{array}$ & Test parameters & Acceptance criteria \\
\hline \multicolumn{3}{|c|}{ Dry mixing (high shear mixer) - Homogenous mixture } \\
\hline $\begin{array}{l}\text { Mixing time, } \\
\text { Impeller } \\
\text { speed }\end{array}$ & $\begin{array}{l}\text { Mixing time } \\
\text { and speed }\end{array}$ & $\begin{array}{c}\text { Mixing time: .... Min } \\
\text { Impeller speed: } \\
\text { (S/M/H) } \pm 5 R P M \\
\text { Content Uniformity: } 90 \% \text { - } \\
110 \% \\
\text { RSD: } \pm 5 \%\end{array}$ \\
\hline \multicolumn{3}{|c|}{$\begin{array}{c}\text { Wet granulation (high shear mixer) - Convert powder to } \\
\text { granules }\end{array}$} \\
\hline $\begin{array}{c}\text { Time, } \\
\text { Temperature, } \\
\text { Solvent used }\end{array}$ & $\begin{array}{c}\text { Mode and time of } \\
\text { addition }\end{array}$ & $\begin{array}{l}\text { Depending up on the } \\
\text { formulation }\end{array}$ \\
\hline \multicolumn{3}{|c|}{$\begin{array}{c}\text { Drying (fluid bed dryer) - reduce moisture content to } \\
\text { proper level }\end{array}$} \\
\hline $\begin{array}{l}\text { Inlet temp, } \\
\text { Outlet temp, } \\
\text { Drying time }\end{array}$ & $\begin{array}{c}\text { Inlet/outlet } \\
\text { temperature and } \\
\text { drying time }\end{array}$ & $\begin{array}{c}\text { Initial drying: } \ldots \ldots . .{ }^{\circ} \mathrm{C} \\
\text { Drying time: } \ldots \ldots . . . \min \\
\text { Final drying: } \ldots \ldots \ldots .^{\circ} \mathrm{C} \pm \\
5{ }^{\circ} \mathrm{C} \\
\text { Loss on drying: } \ldots . . \% \text { below } \\
3 \%\end{array}$ \\
\hline
\end{tabular}

\begin{tabular}{|c|c|c|}
\hline \multicolumn{3}{|c|}{$\begin{array}{c}\text { Milling (Conical mill) - reduce particle size of dried } \\
\text { granulation }\end{array}$} \\
\hline $\begin{array}{l}\text { Mill speed, } \\
\text { Freed rate }\end{array}$ & Milling Speed & $\begin{array}{l}\text { Impeller speed: }(\mathrm{S} / \mathrm{M} / \mathrm{H}) \\
\text { Chopper speed: }(\mathrm{S} / \mathrm{M} / \mathrm{H})\end{array}$ \\
\hline \multicolumn{3}{|c|}{$\begin{array}{c}\text { Final Blending-Lubrication-(Blender) - Provide granules } \\
\text { suitable flow and compressibility } \\
\end{array}$} \\
\hline $\begin{array}{l}\text { Time, } \\
\text { lender speed }\end{array}$ & $\begin{array}{c}\text { Mixing time \& } \\
\text { Speed }\end{array}$ & $\begin{array}{l}\text { Mixing time: ....... Min } \\
\text { Speed: ...... RPM } \\
\text { Content Uniformity: }\end{array}$ \\
\hline
\end{tabular}

Tablet Compression - Manufacture of compressed tablets

\begin{tabular}{|c|c|c|}
\hline $\begin{array}{l}\text { Compression } \\
\text { Speed, } \\
\text { Compression } \\
\text { force }\end{array}$ & $\begin{array}{l}\text { Machin Speed \& } \\
\text { Compression } \\
\text { Force }\end{array}$ & $\begin{array}{c}\text { Average weight: ...... Mg } \\
\text { Uniformity of weight mg: } \\
\text { Thickness: ........ mm } \\
\text { Hardness: ........ N or Kp } \\
\text { Disintegration time: NMT } \\
\ldots \ldots \text { min } \\
\text { Friability: NMT ....... } \\
\text { w/w } \\
\text { Assay: Dissolution: } \\
\text {........... \% }\end{array}$ \\
\hline \multicolumn{3}{|c|}{ Tablet coating - Coating of tablet } \\
\hline $\begin{array}{l}\text { Pan Speed, } \\
\text { Spray rate }\end{array}$ & $\begin{array}{c}\text { Pan speed, } \\
\text { inlet/outlet } \\
\text { temperature, } \\
\text { spray rate }\end{array}$ & $\begin{array}{c}\text { Average weight: ...... mg } \\
\text { Weight of } 20 \text { tablets: ...... } \\
\text { mg } \\
\text { Thickness: ........ mm } \\
\text { Disintegration time: NMT } \\
\text {.... Min } \\
\text { Assay: } \\
\text { Dissolution: ........... \% }\end{array}$ \\
\hline
\end{tabular}

Figure 6 shows three stages of process validation in industries. Statistical process control is one of the critical items should be done during in-process tablet manufacturing. The process should be run at least 3 times to ensure the process qualification and must be examined if the tested parameters would satisfy the acceptance criteria or not.

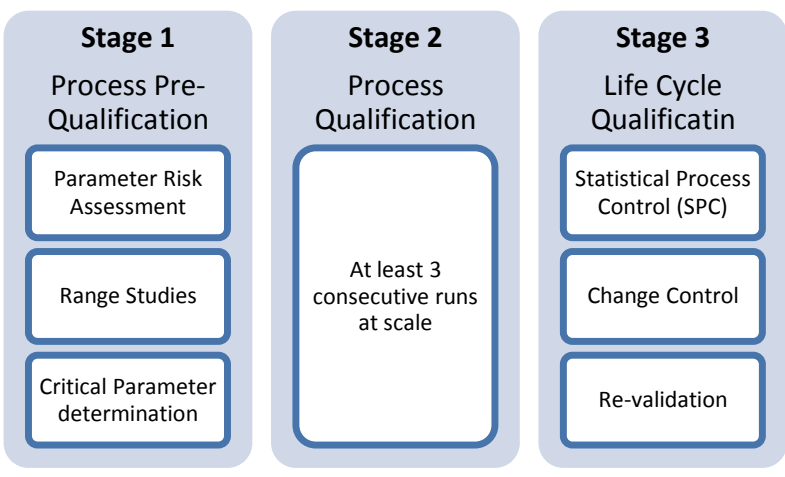

Fig 6: Three Process Validation Stages

\section{CASE STUDY}

\subsection{In Process Control}

Behestan Tolid pharmaceutical company is located in Kaveh Industrial town, Saveh road, Iran. This company is engaged in manufacturing of finished dosage forms of generic and brand medicine. This factory with one Oral Solid Dosage (OSD) production line in non-sterile production area is activated for primary and secondary packaging and production line from API to the finished products like Tablets and Capsules. Behestan Tolid as the manufacturing company of the biggest private pharmaceutical holding, that is Behfar, has been raised and as the most important mission, its manufacturing under 
license for prestigious companies such as Astellas, SandozHexal and couple of American Companies.

This paper wants to show the implementation of SPC include shewhart control charts, Acceptance control charts, and capability analysis within in-process validation. This tablet manufacturing process validation, is done in four consecutive runs and during each run, some of parameters were tested according to the control variables, such as Tablet Hardness, Tablet Thickness, Content Uniformity Test, LOD Test, Friability, Disintegration, Dissolution Tests and etc.

This paper present statistical data analysis in some control parameters within the process validation phase.

\subsubsection{Tablet Hardness}

One of the critical quality attributes which influences tablet coating, packaging, transporting and other process activities is tensile strength we call Tablet Hardness. In this case, the pharmaceutical company would like to evaluate the tablet compression process for a new tablet product (Placebo production for test). Predetermined number of subgroups were taken equally intervals.

The following table displays the test results of individual tablet from 20 consecutive samples of 6 tablets. The results are expressed as the percent of target value. The Lower Specification Level for Tablet Hardness for this case is NLT(Not Less Than) $5 \mathrm{~kg} / \mathrm{cm}^{2}$ and it can be considered 6 as target value.

Table 2. Tablet Hardness Result (Percent of Target value)

\begin{tabular}{|c|cccccc|}
\cline { 2 - 7 } \multicolumn{1}{c}{} & 1 & 2 & 3 & 4 & 5 & 6 \\
\hline $\mathbf{1}$ & 94.4 & 100.4 & 97 & 95.3 & 100.2 & 95 \\
\hline $\mathbf{2}$ & 95.7 & 90 & 96 & 97.8 & 97.2 & 93 \\
\hline $\mathbf{3}$ & 98.7 & 99.6 & 100.5 & 97.3 & 98.6 & 101.3 \\
\hline $\mathbf{4}$ & 97.2 & 95.3 & 94 & 95.6 & 92.3 & 95.6 \\
\hline $\mathbf{5}$ & 93.2 & 95.7 & 98.6 & 99.3 & 97.8 & 92.1 \\
\hline $\mathbf{6}$ & 97.3 & 95.7 & 94.8 & 95.4 & 97.8 & 92.3 \\
\hline $\mathbf{7}$ & 101.3 & 98 & 101.1 & 106.7 & 97 & 96 \\
\hline $\mathbf{8}$ & 95.6 & 95.9 & 97.3 & 94.5 & 102.2 & 97.4 \\
\hline $\mathbf{9}$ & 96.5 & 98.6 & 98.8 & 96.3 & 97.4 & 97.5 \\
\hline $\mathbf{1 0}$ & 94.3 & 94.3 & 97 & 89.7 & 95.8 & 97.6 \\
\hline $\mathbf{1 1}$ & 97.5 & 99.5 & 103.2 & 96.6 & 97.2 & 98 \\
\hline $\mathbf{1 2}$ & 97.6 & 89.8 & 94 & 95 & 100.2 & 98.3 \\
\hline $\mathbf{1 3}$ & 98.3 & 101.3 & 98.9 & 91 & 102.7 & 104.3 \\
\hline $\mathbf{1 4}$ & 92.6 & 94 & 95.2 & 98 & 96.3 & 94.1 \\
\hline $\mathbf{1 5}$ & 99 & 87.3 & 98.7 & 95 & 95.5 & 94.8 \\
\hline $\mathbf{1 6}$ & 98.4 & 94.2 & 93.4 & 90.2 & 91.4 & 101.3 \\
\hline $\mathbf{1 7}$ & 98.8 & 97.8 & 95.6 & 96.2 & 99.3 & 100.1 \\
\hline $\mathbf{1 8}$ & 98 & 95.2 & 97.6 & 97.1 & 97.4 & 98 \\
\hline $\mathbf{1 9}$ & 100.2 & 98.9 & 101.3 & 98.4 & 99.8 & 96.5 \\
\hline $\mathbf{2 0}$ & 97.6 & 95 & 89.4 & 94 & 97.3 & 93.9 \\
\hline
\end{tabular}

First, the Data of individuals, should be tested for normality.

Using Anderson Darling Normality Test, the result shows that because the P-Value is greater than $\alpha=0.05$ so the normality test result is positive and the data can be considered as Normal.

Figure 7 shows the schematic presentation of Normality Test.

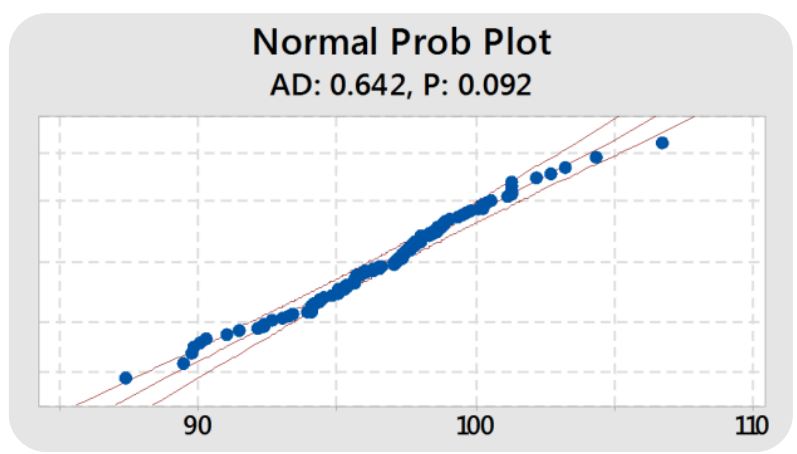

Fig 7: Normal Probability Test

Because the number of each sample is 6 , the $\mathrm{Xbar} / \mathrm{R}$ chart is used to control the mean and deviation of data. Figure 8 shows the $\mathrm{Xbar} / \mathrm{R}$ control charts and it means that the variability of subgroup means is in control.

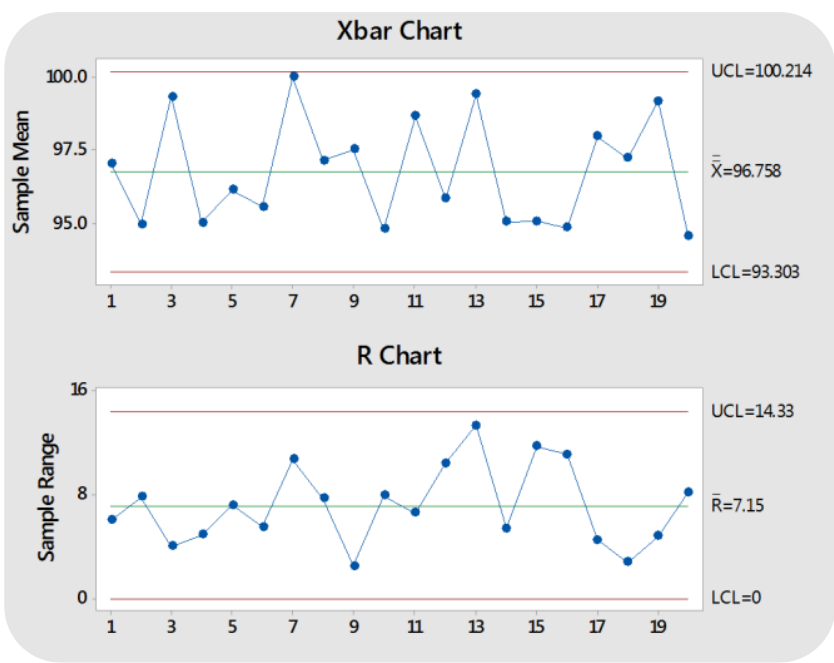

Fig 8: $\mathrm{Xbar} / \mathrm{R}$ chart control results

The figure shows that all sub-group means are within the UCL and LCL for both charts and it demonstrate that no special causes are present and there are no statistically important differences between all sub-group means. But it can be considered that the $7^{\text {th }}$ group have a mean very close to the upper control limit which means that it's in warning situation.

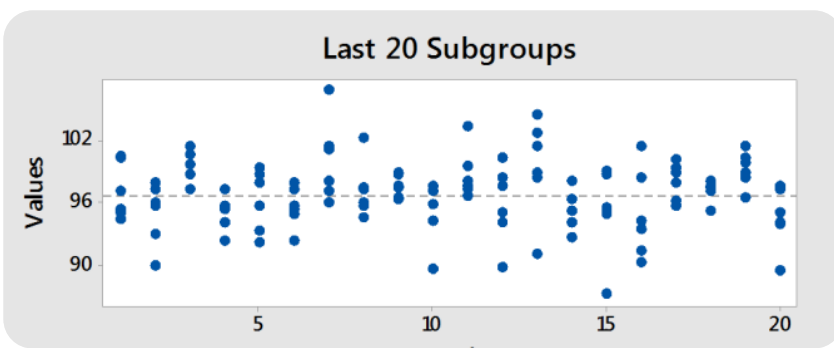

Fig 9: Values of tablet hardness plotted in subgroups

One of the data in $7^{\text {th }}$ group (Sample7, Data: 106.7) is greater than others caused the mean of this group, closer to UCL. This matter is not uncommon in this stage.

According to the Upper and lower specification Levels, the process capability analysis is done and the result has shown in figure 10 . 

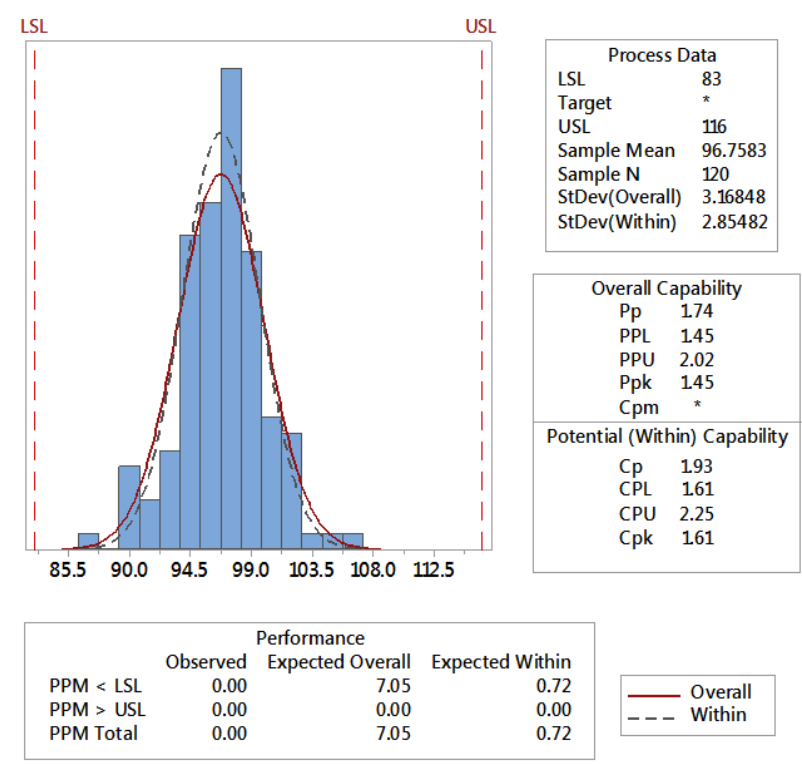

Fig 10: Process Capability Report for Tablet Hardness

To interpret the Capability Analysis results, it could be said, the Process capability index (CPk) about 1.61demostrates that the process is robust and it assures that the current production sample meet the specifications in excellent condition. The process performance (PPk) with the value of 1.45 illustrates that the process could meet the specifications in the long run. The proximity of the two, shows that the adjacency of the deviation of data, in both "within" and "overall" which shows the uniformity of variation, over time. It is expected that the number of defective tablets is less than 7 per million in overall.

To work in 6-sigma program, the process should be ran with less than 3.4 defectives per million which means the process average just could shift to \pm 1.5 standard deviations, which yields about 4.5 sigma quality level.

According to ISO 7966, the acceptance chart could be plotted according to the mentioned formulas:

$\sigma_{\overline{\mathrm{x}}}=1.152 \quad \& \quad \sigma_{\mathrm{x}}=2.854$

$\mathrm{APL}_{\mathrm{u}}=$ Mean $+1.5 \sigma_{\mathrm{x}}=100+1.5 \times 2.854=104.281$

$\mathrm{APL}_{\mathrm{l}}=$ Mean $-\mathrm{k}_{1} \sigma_{\mathrm{x}}=100-1.5 \times 2.854=95.719$

$\mathbf{A C L}_{\mathbf{u}}=\mathrm{APL}_{\mathbf{u}}+3 \sigma_{\overline{\mathbf{x}}}=104.281+3 \times 1.152=\mathbf{1 0 7 . 7 3 7}$

$\mathbf{A C L}_{\mathbf{l}}=\mathrm{APL}_{\mathrm{l}}-3 \sigma_{\overline{\mathrm{x}}}=95.719-3 \times 1.152=\mathbf{9 2 . 2 6 3}$

Pending sample means exist between 92.263 \& 107.737 it will be accepted (with the probability of 0.997 ) that the process mean stays within \pm 1.5 standard deviation of target value of 100.

Figure 11 shows the acceptance control chart plotted for tablet hardness control variable. It is obvious that all of Sample Means are between the ACLs acceptance control limits, so this process could produce under Six-Sigma quality level.

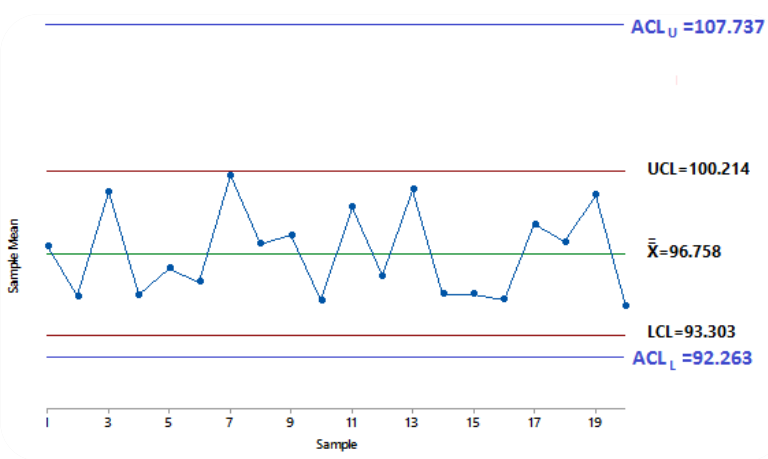

Fig 11: Acceptance chart for Hardness Variable

\subsubsection{Weight Variation Test}

In this test, every 30 minutes, 20 tablets are weighed and the specification range for the weight of the tablet is $100 \pm 2 \mathrm{mg}$ per tablet. The shewhart control charts shows the variation of subgroup means. Table 3 shows the weight data sampled within the compression process.

Table 3. weight sampling data

\begin{tabular}{|c|c|c|c|c|c|c|c|c|c|c|}
\hline SG & $\mathbf{1}$ & $\mathbf{2}$ & $\mathbf{3}$ & $\mathbf{4}$ & $\mathbf{5}$ & $\mathbf{6}$ & $\mathbf{7}$ & $\mathbf{8}$ & $\mathbf{9}$ & $\mathbf{1 0}$ \\
\hline $\mathbf{1}$ & 101 & 100 & 101 & 101 & 100 & 101 & 100 & 98 & 100 & 100 \\
\hline $\mathbf{2}$ & 102 & 101 & 100 & 100 & 99 & 98 & 98 & 99 & 99 & 102 \\
\hline $\mathbf{3}$ & 99 & 101 & 99 & 102 & 102 & 102 & 99 & 101 & 101 & 101 \\
\hline $\mathbf{4}$ & 100 & 99 & 102 & 98 & 98 & 101 & 98 & 100 & 102 & 102 \\
\hline $\mathbf{5}$ & 102 & 101 & 98 & 102 & 99 & 102 & 98 & 101 & 98 & 98 \\
\hline $\mathbf{6}$ & 100 & 102 & 99 & 101 & 100 & 100 & 101 & 101 & 101 & 99 \\
\hline $\mathbf{7}$ & 101 & 101 & 100 & 102 & 100 & 101 & 98 & 100 & 101 & 100 \\
\hline $\mathbf{8}$ & 99 & 100 & 101 & 102 & 98 & 98 & 99 & 102 & 102 & 98 \\
\hline $\mathbf{9}$ & 102 & 99 & 99 & 100 & 99 & 99 & 101 & 99 & 101 & 99 \\
\hline $\mathbf{1 0}$ & 100 & 100 & 98 & 101 & 101 & 102 & 100 & 98 & 100 & 99 \\
\hline $\mathbf{1 1}$ & 101 & 100 & 102 & 100 & 102 & 101 & 102 & 98 & 101 & 100 \\
\hline $\mathbf{1 2}$ & 102 & 98 & 100 & 98 & 100 & 100 & 98 & 99 & 98 & 101 \\
\hline $\mathbf{1 3}$ & 99 & 99 & 99 & 99 & 98 & 102 & 99 & 101 & 99 & 100 \\
\hline $\mathbf{1 4}$ & 98 & 102 & 101 & 102 & 99 & 101 & 101 & 99 & 101 & 102 \\
\hline $\mathbf{1 5}$ & 101 & 101 & 102 & 102 & 100 & 101 & 99 & 98 & 99 & 101 \\
\hline $\mathbf{1 6}$ & 102 & 99 & 100 & 101 & 101 & 98 & 98 & 100 & 98 & 98 \\
\hline $\mathbf{1 7}$ & 100 & 99 & 101 & 101 & 100 & 99 & 99 & 100 & 102 & 102 \\
\hline $\mathbf{1 8}$ & 101 & 101 & 98 & 101 & 102 & 101 & 99 & 99 & 99 & 100 \\
\hline $\mathbf{1 9}$ & 99 & 99 & 99 & 102 & 101 & 100 & 100 & 99 & 98 & 101 \\
\hline $\mathbf{2 0}$ & 102 & 102 & 98 & 102 & 101 & 100 & 98 & 100 & 98 & 99 \\
\hline
\end{tabular}

Because the sample number is 20 , the $\mathrm{Xbar} / \mathrm{S}$ chart was used to analyze the common or special causes variations. Figure 12 shows the related charts. It's obvious that there is no special cause variation during the process in both mean and standard deviation so the process is in control. But as it could be considered, the $4^{\text {th }}$ subgroup mean is very closer to UCL than the other means. the $7^{\text {th }}$ mean has such situation, too. The $4^{\text {th }}$ and $7^{\text {th }}$ subgroup are in warning area.

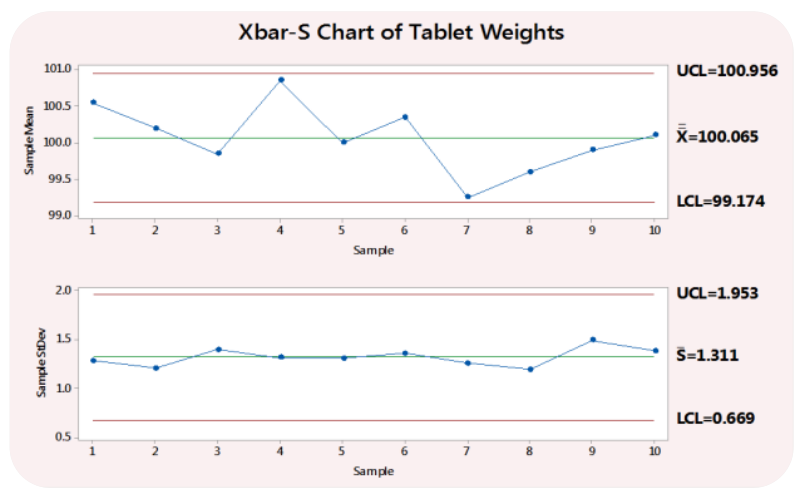

Fig 12: Xbar-S chart for tablet weights 
The warning area are defined between the 2 and 3 standard deviation of mean distribution so the Upper Warning Limit(UWL) and Lower Warning Limit (LWL) are plotted to show the tendency of process mean to be fell out the Control Limits in near future. Figure 13 show the Zone Chart of Weights which can help to classify the Control Area according to the Standard deviation distances.

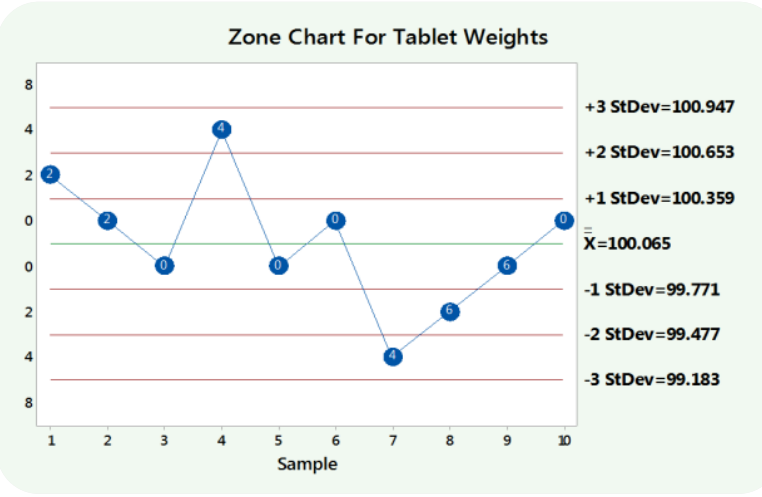

Fig 13: Zone Chart of Tablet Sampling Weights

The zone chart illustrates that the $4^{\text {th }}$ and $7^{\text {th }}$ subgroup mean are in Warning Area so there are no more than 2 in 10 values between the waring and action limits.

\subsubsection{Tablet Thickness}

Tablet thickness is another critical attribute should be controlled within the manufacturing process to facilitate the packaging. Usually the thickness have to be controlled within the target value $\pm 5 \%$ variation of the standard. The first thickness control is performed in compress operation. To control the thickness, 20 subgroups include 6 parts each sample would be taken once every 10 minutes. In this case the specification limits defined as $2.2 \pm 0.2 \mathrm{~mm}$. So the upper specification limit could be considered as 2.4 and lower specification limit as 2 . Table 4 shows the sampling data gathered for thickness variable.

Table 4. Tablet Thickness Result

\begin{tabular}{|c|cccccc|}
\cline { 2 - 7 } \multicolumn{1}{c|}{} & 1 & 2 & 3 & 4 & 5 & 6 \\
\hline $\mathbf{1}$ & 2.17 & 2.26 & 2.25 & 2.24 & 2.23 & 2.23 \\
\hline $\mathbf{2}$ & 2.27 & 2.27 & 2.28 & 2.29 & 2.32 & 2.2 \\
\hline $\mathbf{3}$ & 2.22 & 2.25 & 2.25 & 2.26 & 2.29 & 2.25 \\
\hline $\mathbf{4}$ & 2.23 & 2.28 & 2.2 & 2.23 & 2.25 & 2.24 \\
\hline $\mathbf{5}$ & 2.27 & 2.25 & 2.24 & 2.23 & 2.27 & 2.22 \\
\hline $\mathbf{6}$ & 2.23 & 2.25 & 2.22 & 2.25 & 2.24 & 2.24 \\
\hline $\mathbf{7}$ & 2.25 & 2.25 & 2.28 & 2.29 & 2.23 & 2.26 \\
\hline $\mathbf{8}$ & 2.24 & 2.23 & 2.25 & 2.25 & 2.26 & 2.24 \\
\hline $\mathbf{9}$ & 2.23 & 2.25 & 2.25 & 2.22 & 2.24 & 2.26 \\
\hline $\mathbf{1 0}$ & 2.26 & 2.23 & 2.22 & 2.24 & 2.25 & 2.25 \\
\hline $\mathbf{1 1}$ & 2.22 & 2.23 & 2.23 & 2.25 & 2.21 & 2.24 \\
\hline $\mathbf{1 2}$ & 2.25 & 2.26 & 2.25 & 2.23 & 2.2 & 2.23 \\
\hline $\mathbf{1 3}$ & 2.24 & 2.28 & 2.27 & 2.25 & 2.24 & 2.27 \\
\hline $\mathbf{1 4}$ & 2.22 & 2.19 & 2.25 & 2.25 & 2.26 & 2.24 \\
\hline $\mathbf{1 5}$ & 2.25 & 2.23 & 2.27 & 2.21 & 2.2 & 2.23 \\
\hline $\mathbf{1 6}$ & 2.26 & 2.25 & 2.25 & 2.22 & 2.24 & 2.23 \\
\hline $\mathbf{1 7}$ & 2.26 & 2.21 & 2.23 & 2.24 & 2.22 & 2.26 \\
\hline $\mathbf{1 8}$ & 2.22 & 2.24 & 2.26 & 2.25 & 2.26 & 2.23 \\
\hline $\mathbf{1 9}$ & 2.24 & 2.21 & 2.28 & 2.25 & 2.25 & 2.24 \\
\hline $\mathbf{2 0}$ & 2.24 & 2.23 & 2.25 & 2.26 & 2.23 & 2.24 \\
\hline
\end{tabular}

Figure 14 shows the subgroup mean fluctuations around the central line. The second subgroup mean is out of control range. So the special cause happened within that sampling period of time. The cause and effect diagram could be plotted to detect the reasons of this special variation.

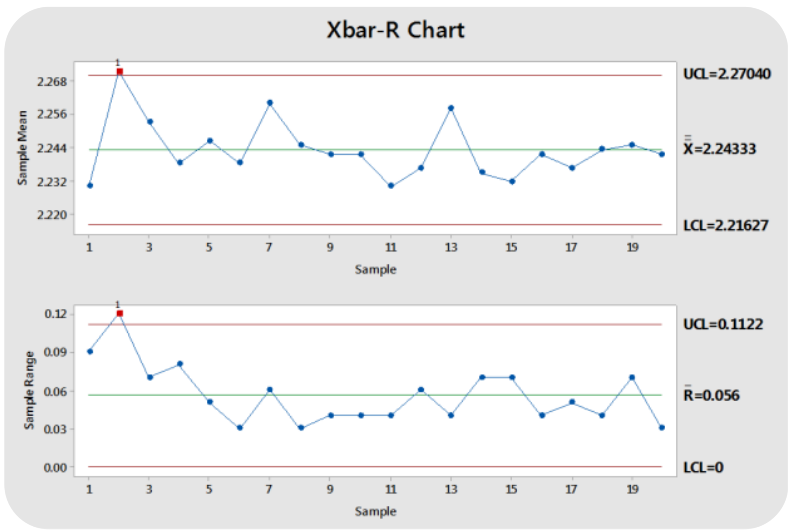

Fig 14: Control charts for Tablet Thickness

In this situations, the problems cause this out of range variation, should be identified and corrected. In some cases, the rout cause analysis (RCA) may be required to find the special cause of the variation in the second subgroup.

\section{CONCLUSION}

This paper reviewed the statistical quality control of three inprocess control variable, Hardness, Weight and Tablet thickness for Placebo production process. The required control charts include shewhart control charts and acceptance control charts are plotted in six-sigma and the results analyzed as well as the capability analysis of data according their specification limits have been done. As described in Fig 6, it is necessary to run the process at least three consecutive times to compare the related results and judge the qualification and validation of the process. In future the use of statistical method for process qualification will be considered.

\section{ACKNOWLEDGMENTS}

My thanks to the All Behestan Tolid experts and management cadre who have contributed towards development of the paper.

\section{REFERENCES}

[1] Freund, R.A. (1975). Acceptance control charts. Industrial quality control, 14(4), 13-23.

[2] Duncan, A.J. 1986. quality control and industrial applications. $5^{\text {th }}$ edition. Homewood, Illinois: Irwin.

[3] Montgomery, D.C. (1996). Introduction to statistical quality control. $3^{\text {th }}$ edition, Wiley.

[4] Tavel, P. 2007 Modeling and Simulation Design. AK Peters Ltd.

[5] Geoff, T. 2001. Six sigma: SPC and TQM in manufacturing and services.

[6] Hary, M.J. "Six- sigma: A breakthrough strategy for profitability, 31(5), 60-64.

[7] Chiarini, A. 2011. Japanese total quality control, TQM, Deming's system of profound knowledge, BPR, lean and 6 sigmas: Comparison and discussion. International journal of lean six sigma, 2(4), 332-355. 
[8] Patel, H., and Thaker, A. 2015. Statistical process control as a tool to control weight uniformity of tablets. Journal of pharmacy and applied science. 2(1), 8-15.

[9] Hashmat, D., Shoaib, M.H., Mehmood, Z.A., Bushra, R., Yousuf, R.I., and Lakhani, F.2008. Development of Enteric Coated Flurbiprofen Tablets using Opadry/acryleze System-A Technical Note. AAPS PharmSciTech; 9: 116-121.
[10] Brochmann. E., and Medin, J.C. 2006. Dosage Variation in Tablets. Journal of Pharmaceutical Sciences; 52: 630-633.

[11] Surbhi, G., Seema, S., Gurpreet, S. and Rana, A.C. 2012. Industrial Process Validation of Tablet Dosage from. International research journal of pharmacy. 3(3) 48-54. 